\title{
Quantum Mechanics-Based Structure Analysis of Cyclic Monoterpene Glycosides from Rhodiola rosea
}

Yu Tang, ${ }^{\dagger}$ J. Brent Friesen, ${ }^{\ddagger}$, David C. Lankin,$^{\dagger}$ James B. McAlpine, ${ }^{\dagger}$ Dejan Nikolić, ${ }^{\dagger}$ Matthias Niemitz, ${ }^{\perp}$ David S. Seigler, $\Perp$ James Graham, Shao-Nong Chen, ${ }^{\dagger, *}$ Guido F. Pauli ${ }^{\dagger, *}, *$

'UIC/NIH Center for Botanical Dietary Supplements Research, Program for Collaborative Research in the Pharmaceutical Sciences (PCRPS) and Department of Pharmaceutical Sciences, College of Pharmacy, University of Illinois at Chicago, 833 S. Wood St., Chicago, IL 60612, United States

${ }^{\star}$ Center for Natural Product Technologies (CENAPT), Program for Collaborative Research in the Pharmaceutical Sciences (PCRPS) and Department of Pharmaceutical Sciences, College of Pharmacy, University of Illinois at Chicago, 833 S. Wood St., Chicago, IL 60612, United States

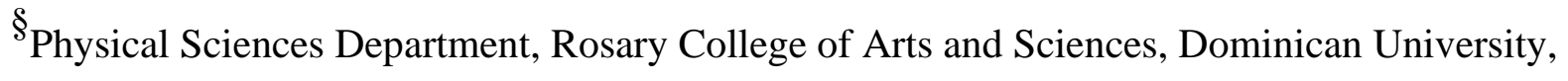
River Forest, IL 60305, United States

${ }^{\perp}$ NMR Solutions Ltd., Puijonkatu 24 B 5, 70110 Kuopio, Finland

"Department of Plant Biology, University of Illinois at Urbana Champaign, Urbana Champaign, IL 61801, United States 
Abstract: NMR- and MS-guided metabolomic mining for new phytoconstituents from a widely used dietary supplement, Rhodiola rosea, yielded two new (+)-myrtenol glycosides, $\mathbf{1}$ and $\mathbf{2}$, and two new cuminol glycosides (3 and 4), along with three known analogues (5-7). The structures of the new compounds were determined by extensive spectroscopic analysis. Quantum Mechanicsdriven ${ }^{1} \mathrm{H}$ iterative Full Spin Analysis (QM-HiFSA) decoded the spatial arrangement of the methyl groups in $\mathbf{1}$ and $\mathbf{2}$, as well as other features not recognizable by conventional methods, including higher order spin-coupling effects. The application of QM-HiFSA will provide a definitive reference point for future phytochemical and biological studies of $R$. rosea as a resilience botanical. Application of a new NMR data analysis software package, CT, for QM-based iteration of NMR spectra is also discussed. 
Rhodiola rosea L. (commonly known as roseroot, rose root, or goldenroot) has emerged as a popular botanical dietary supplement exhibiting adaptogenic effects in situations of decreased performance such as fatigue and sensation of weakness. ${ }^{1-3}$ The adaptogenic or resilienceenhancing activities of this plant are purported to increase the body's nonspecific resistance, reduce stress-induced impairments and ameliorate disorders to neuro-endocrine and immune systems. ${ }^{1-3}$ The underground parts of $R$. rosea have been used in folk medicine in the western Siberia Region of Russia, particularly in the Altai region, as means of relieving fatigue and increasing energy, especially during extended periods of strenuous activity. Traditional use of $R$. rosea as a tonic in Siberian and Russian medicine stimulated extensive research leading to early experimental research revealing that $R$. rosea prolonged endurance in a number of animal studies, as well as clinical evaluations that showed a clear stimulating effect on mental activity and on the magnitude and intensity of mechanical work, particularly against a background of fatigue. ${ }^{4}$

A comprehensive literature survey revealed that the major constituents in this plant are proanthocyanidins, phenylpropanoids, phenylethanoids, flavonoids, monoterpenoids, and cyanogenic glycosides. However, documented pharmacological and mechanistic studies mainly focus on Rhodiola extract, salidroside (a phenylethanoid) and the rosavins (phenylpropanoids) as its major constituents. While monoterpenes are widely distributed in $R$. rosea, they have not been studied systematically, and only a few investigations have described the bioactivity of Rhodiola monoterpenes. A report by van Diermen et al. concluded that extracts of $R$. rosea showed a potentially beneficial effect associated with depression and senile dementia. ${ }^{5}$ Moreover, a monoterpene glycoside, rosiridin, obtained from the extract by bioassay-guided isolation showed the highest activity among the isolates. ${ }^{5}$ However, from a bioactivity and mechanism-of action as well as from a chemodiversity perspective, $R$. rosea can be considered underexplored, especially as the monoterpenoids occurring in this species likely play a role in the adaptogenic effect. Thus, it was considered of interest to explore the structural diversity of $R$. rosea monoterpenoids in order to potentially offer new aspects in botanical adaptogen research.

Due to the polarity characteristics of monoterpene glycosides, a centrifugal partition chromatography (CPC) technique played a critical role in the separation workflow. CPC has become increasingly useful in natural products research due to its liquid-only character, which results in minimal sample loss as well as in its ability to target specific metabolites via the fine tuning of biphasic solvent systems. ${ }^{6,7}$ 
An enduring analytical challenge relates to stereochemical assignments of monoterpene glycosides, both for the aglycone and the sugar moieties. The occurrence of higher order coupling effects is prominent in these compounds, resulting from the proximity of highly coupled hydrogens in both the monoterpene and the sugar moieties. Quantum Mechanics-based ${ }^{1} \mathrm{H}$ full Spin Analysis (QM-HiFSA) was employed to facilitate structural characterization. HiFSA enabled the extraction of highly accurate $J$ and $\delta$ values, despite the presence of complex, non-first-order spin systems. ${ }^{8,9}$

\section{- RESULTS AND DISCUSSION}

Cyclic Monoterpene Glycosides from $\boldsymbol{R}$. rosea. Four pinane glycosides $(\mathbf{1}, \mathbf{2}, \mathbf{5}$, and $\mathbf{6})$ together with three menthane glycosides $(\mathbf{3}, \mathbf{4}$, and 7) were isolated from the rhizomes/roots of $R$. rosea. Among the isolates were four new structures, including two myrtenol glycosides, $\mathbf{1}$ and $\mathbf{2}$, and two cuminol glycosides, 3 and $\mathbf{4}$. The structures of the new compounds were determined by a combination of 1D/2D NMR spectroscopy, LC-MS, and QM-HiFSA.

Higher Order Effects and Structural Analysis of the Sugar Residue of Glycosides. The pyranoid forms of glucose (glcp) and arabinose (arap), as well as the furanoid form of arabinose (araf) are the predominant sugar moieties in Rhodiola monoterpene glycosides. ${ }^{1,10}$ In this study, the assignment of glucose and arabinose to their D- and L-series was based largely on the close matching of the ${ }^{1} \mathrm{H}$ and ${ }^{13} \mathrm{C}$ NMR resonances relative to corresponding resonance in the literature in combination with enzymatic hydrolysis. The ${ }^{1} \mathrm{H}$ NMR spectra of sugar moieties are readily misinterpreted due to the presence of higher order spin coupling effects. ${ }^{8,9}$ Such effects are caused whenever the chemical shift differences $(\Delta \delta)$ and coupling constants $(J)$ of resonances within a spin system are of similar magnitude. ${ }^{8,9}$ Notably, such instances are very abundant in natural products and other organic compounds, and frequently lead to the designation of "multiplets" and corresponding lack of constitutional and configurational evidence.

Precise ${ }^{1} \mathrm{H}$ NMR profiles of the four new compounds, 1-4, were generated using the PERCH NMR iteration software ${ }^{11}$ to unambiguously assign the partially complex signals of the sugar moieties (Table 1). In contrast to the glucose moiety present in $\mathbf{2}$ and $\mathbf{4}$, the counterparts in $\mathbf{1}$ and 3 represent prototypical examples of higher order effects (Figure 1). The ${ }^{1} \mathrm{H}$ NMR signals of H-2' and $\mathrm{H}^{-} 5^{\prime}$ in the $\beta$-glucose moieties of $\mathbf{1}$ and $\mathbf{3}$ are subject to particularly pronounced higher order effects. The deviations of the signals of $\mathrm{H}-2^{\prime}$ and $\mathrm{H}-5^{\prime}$ from the expected dd and ddd spin patterns, respectively, can be explained by the close resonance proximity between their directly coupled 
neighbors, $\mathrm{H}-3^{\prime}$ and $\mathrm{H}-4^{\prime}$, which show only very subtle differences in their chemical shifts $(\Delta \delta)$ of only $9.3 \mathrm{ppb}$ in $\mathbf{1}$ and $11.0 \mathrm{ppb}$ in $\mathbf{3}$, which can be readily determined even at $400 \mathrm{MHz}$. When elucidating the relative configuration of the sugar residues of an unknown Rhodiola monoterpene, $\mathrm{H}-2^{\prime}$ has the potential to serve as a ${ }^{1} \mathrm{H}$ NMR marker signal. This is owing to the fact that its chemical shift resides in a relatively uncrowded region of the spectrum, while the higher order effects are caused by the resonance proximity of H-3' and H-4'. As shown in Figure 1, both $\mathbf{1}$ and $\mathbf{3}$ contain the $\alpha$-L-arabinopyranosyl-( $(\rightarrow 6)-\beta$-D-glucopyranosyl residue, in which H-2' shows relatively complex ${ }^{1} \mathrm{H}$ NMR patterns. While $\mathrm{H}-2^{\prime}$ in $\mathbf{2}$ and $\mathbf{4}$ containing the $\beta$-D-glucopyranosyl and $\alpha$-L-arabinofuranosyl-( $1 \rightarrow 6)-\beta$-D-glucopyranosyl groups, respectively, show the more tripletlike peak pattern. While slightly different from the triplet-like splitting pattern of $\mathrm{H}-2^{\prime}$ in $\mathbf{2}$, upon closer inspection, the signal for $\mathrm{H}^{2} \mathbf{2}^{\prime}$ in $\mathbf{4}$ shows a pseudo triplet-like splitting pattern (Figure S21, Supporting Information).

Due to the signal overlap of the residual solvent $\left(\mathrm{CHD}_{2} \mathrm{OD}\right)$ signal with the resonances of $\mathrm{H}-3^{\prime}$ and H-4' in both 2 and 4, 1D TOCSY spectra were acquired. Detailed inspection of these spectra showed that the outer sub-peaks of H-3' and H-4' in $\mathbf{4}$ are superimposed (Figure 1) at $400 \mathrm{MHz}$, while the outer sub-peaks of $\mathrm{H}-3^{\prime}$ and $\mathrm{H}-4^{\prime}$ in $\mathbf{2}$ are resolved. This observation indicates that the higher order effects have a tendency to be more obvious whenever the (sub)peaks of neighboring hydrogen resonances overlap. Such an overlap of outer (sub)-peaks of adjacent hydrogens can be regarded as diagnostic for the presence of higher order effects. In such situations, the conventional determination of $J$ values by manual measurement of line distances inevitably leads to significant errors: measured intervals between peaks are primarily line distances, not coupling constants. For example, $\mathrm{H}-2^{\prime}$ in $\mathbf{1}$ and $\mathbf{3}$ appears as a multiplet with more than two couplings from a point-ofview of splitting pattern. However, the QM-HiFSA revealed that H-2' is a "higher order dd" resulting from two couplings and all the higher order spin coupling behavior which is due to the proximity of the resonances of the coupled H-3' and next-coupled H-4'. Collectively, the QMHiFSA approach can provide precise and field independent $\delta / J$ values for the identification and rapid dereplication of congeneric compounds by commonly available $1 \mathrm{D}^{1} \mathrm{H}$ NMR.

Structure Elucidation of Compounds 1 and 2. Both compounds were obtained as colorless solids, and their molecular formulae were determined as $\mathrm{C}_{21} \mathrm{H}_{34} \mathrm{O}_{10}$ and $\mathrm{C}_{16} \mathrm{H}_{26} \mathrm{O}_{6}$, respectively, by HRESIMS. The hydrogen signals in the $\delta 3.1-4.4 \mathrm{ppm}$ region of the ${ }^{1} \mathrm{H}$ NMR spectra indicated that $\mathbf{1}$ and $\mathbf{2}$ contained a disaccharide and a monosaccharide moiety, respectively. These 
substituents were identified as an $\alpha$-L-arabinopyranosyl-( $1 \rightarrow 6)-\beta$-D-glucopyranosyl and a $\beta$-Dglucopyranosyl residue. Additionally, the ${ }^{1} \mathrm{H}$ NMR spectra of $\mathbf{1}$ and $\mathbf{2}$ (Table 2) showed a pair of geminal methyls around $\delta 0.85$ and $1.31 \mathrm{ppm}$ attached to a quaternary carbon, as well as an olefinic hydrogen resonating around $\delta 5.58 \mathrm{ppm}$ (tt-like). All of the data appeared to resemble the NMR data for (-)-myrtenyl $\alpha$-L-arabinopyranosyl-( $1 \rightarrow 6)-\beta$-D-glucopyranoside (5) and (-)-myrtenyl $\beta$ D-glucopyranoside (6). These are characteristic of a compound class common to Rhodiola species. ${ }^{12}$ The only obvious difference between the two pairs of compounds was that the H-10 methylene hydrogens exhibited a $\Delta \delta_{\mathrm{H}-10 \mathrm{a}, \mathrm{H}-10 \mathrm{~b}}$ around $0.09 \mathrm{ppm}$ for $\mathbf{1}$ and $\mathbf{2}$ and around $0.21 \mathrm{ppm}$ for 5 and 6, respectively (Figure 2). Moreover, 2D NMR data (COSY, HSQC, and HMBC) revealed that the aglycone of all four compounds shared the same planar structure. Collectively, the array of acquired spectroscopic data was most compatible with the conclusion that $\mathbf{1}$ and $\mathbf{2}$ share the stereochemically identical aglycone, and that this moiety is the enantiomeric counterpart of the aglycone in 5 and $\mathbf{6}$. Consequently, 1 and 2 were identified as (+)-myrtenyl $\alpha$-Larabinopyranosyl-(1 $\rightarrow 6)-\beta$-D-glucopyranoside and $(+)$-myrtenyl $\beta$-D-glucopyranoside, respectively. This marks the first report of an enantiomeric aglycone among Rhodiola monoterpene glycosides.

HiFSA Analysis of 1. In order to corroborate the structural assignments and facilitate the future structural dereplication of congeneric myrtenol glycosides from Rhodiola species and other organisms, the spin-spin coupling patterns in $\mathbf{1}$ and $\mathbf{2}$ were analyzed via the QM-HiFSA method ${ }^{13}$ using the PERCH NMR software tools. Briefly, the key ${ }^{1} \mathrm{H}$ spin parameters $\left(\delta_{\mathrm{H}},{ }^{\mathrm{n}} J_{\mathrm{H}, \mathrm{H}}\right)$ were predicted and then optimized in the PERCH iterator using D- and T- modes for integral-transform fitting and total-line shape fitting, respectively, until the root-mean-square (RMS) differences were less than 0.1 (final values: 0.030 for 1; 0.042 for 2), indicating excellent agreement between calculated and experimental data (Figure 3). Specifically, this analysis revealed, taking 1 for example, that the geminal hydrogens at C-6 displayed conspicuously different signal patterns. The Quantum Interaction and Linkage Table (QuILT) (Figure 4) is a QM-HiFSA based $J$-correlation map that enables the analysis of a homonuclear data set and allows the structural assignments to be based on clearly defined relationships. ${ }^{14}$ The signal for H-6a appeared as a ddd and exhibited a large ${ }^{2} J$ coupling of $-8.67 \mathrm{~Hz}$ to its geminal partner, as well as two mid-sized ${ }^{3} J$ couplings of 5.42 and $5.83 \mathrm{~Hz}$ to its neighbors $\mathrm{H}-1$ and $\mathrm{H}-5$, respectively. In contrast, $\mathrm{H}-6 \mathrm{~b}$ appeared with reduced multiplicity as a doublet only, although it also has ${ }^{3} J$ coupling relationships with $\mathrm{H}-1$ and $\mathrm{H}-5$. The 
iterative QM-based analysis showed that these coupling constants were $<1 \mathrm{~Hz}$, indicative of nearly $90^{\circ}$ dihedral angles.

The lack of a detectable coupling between $\mathrm{H}-6 \mathrm{~b}$ and $\mathrm{H}-1$ indicated that the ddd splitting pattern of the signals of $\mathrm{H}-1$, which is adjacent to $\mathrm{H}_{2}-6$, should result from long-range couplings. Closer inspection of the QM-HiFSA profile revealed an exceptionally large ${ }^{4} J \mathrm{~W}$-coupling of $5.84 \mathrm{~Hz}$ to $\mathrm{H}-5$, in addition to $\mathrm{a}^{4} \mathrm{~J}$ coupling of $-1.43 \mathrm{~Hz}$ to $\mathrm{H}-3$, which altogether explains the ddd resonance pattern for $\mathrm{H}-1$. The remarkable magnitude of the ${ }^{4} J_{\mathrm{H}-1, \mathrm{H}-5} \mathrm{~W}$-coupling together with unobservable ${ }^{3} J_{\mathrm{H}-1, \mathrm{H}-6 \mathrm{~b}}$ and ${ }^{3} J_{\mathrm{H}-5, \mathrm{H}-6 \mathrm{~b}}$ coupling constants are in line with prior observations of cyclobutane $\mathrm{H}, \mathrm{H} J-$ coupling relationships. ${ }^{14,15}$

Another intriguing observation was that both singlet-like Me-8 and Me-9 resonances exhibited several ${ }^{4} J$ and ${ }^{5} J$ long-range couplings (Figure 4). Among these long-range couplings, the ${ }^{5} J$ coupling between Me-9/H-4a $(0.48 \mathrm{~Hz})$, resulting from the planar 5-bond zigzag arrangement, enabled the determination of the positioning of $\mathrm{H}-4 \mathrm{a}$ and Me-9 as being $\alpha$-oriented (Figure 5). Utilizing the QM-HiFSA derived, highly precise chemical shifts, Me-9 could be irradiated with high selectivity to generate a homonuclear decoupled 1D ${ }^{1} \mathrm{H}$ NMR spectrum of 1 (Figure 6). The existence of a ${ }^{5} J_{\mathrm{H}-4 \mathrm{a}, \mathrm{H}-9}$ zig-zag coupling pathway was further confirmed by this homodecoupling experiment.

Finally, prominent mutual cross peaks between Me-8/H-4b and Me-9/H-6a in the NOESY spectrum (Figure S-6, Supporting Information) unambiguously reconfirmed the assignment that was first based on the QM-HiFSA analysis. Moreover, additional ${ }^{5} J$ couplings between Me-9/H4a and Me-9/H-6a $(0.17 \mathrm{~Hz})$ were detected that explain why the peak height of the Me-9 resonance was slightly lower than that of Me-8, thereby contributing to the precise assignment of the Me- 8 and Me-9 resonances. In an addition to the aforementioned long-range couplings, additional three allylic $\left({ }^{4} J_{\mathrm{H}-1, \mathrm{H}-3},{ }^{4} J_{\mathrm{H}-3, \mathrm{H}-10 \mathrm{a}}\right.$ and $\left.{ }^{4} J_{\mathrm{H}-3, \mathrm{H}-10 \mathrm{~b}}\right)$ and four homoallylic couplings $\left({ }^{5} J_{\mathrm{H}-4 \mathrm{a}, \mathrm{H}-10 \mathrm{a}},{ }^{5} J_{\mathrm{H}-4 \mathrm{a}, \mathrm{H}-10 \mathrm{~b}}\right.$, ${ }^{4} J_{\mathrm{H}-4 \mathrm{a}, \mathrm{H}-10 \mathrm{a}}$ and ${ }^{4} J_{\mathrm{H}-4 \mathrm{~b}, \mathrm{H}-10 \mathrm{~b}}$ ) were observed in the QuiLT (Figure 4) in the 1.2-2.3 Hz range. Again, QM-HiFSA based QuiLT facilitates the verification of all coupling constants and detection of long-range couplings $(\geq 4 \mathrm{~J})$. Therefore, it has the potential to serve as a useful tool to advance structural analysis, especially for those compounds like $\mathbf{1}$ containing allylic, homoallylic, and Wtype couplings. Although PERCH is no longer available commercially, ${ }^{16}$ the QM-based line-shape calculation is featured in other available software, such as CT (currently in beta stage) and ChemAdder (currently in alpha stage). ${ }^{17,18}$ The consistency of HiFSA results achieved with 
different tools was assessed using the CT (Cosmic Truth) software, using $\mathbf{1}$ as a test case. After the PERCH generated initial MMS file was modified according to the final PMS file, the former was imported into CT and then optimized by automatic quantum mechanics iteration until an agreement between the calculated and the experimental spectrum was reached (Figure S-8, Supporting Information). As shown in Figure 7, the CT generated $J$ and $\delta$ values highly resemble those of PERCH with largest $\Delta \delta$ and $\Delta J$ of $0.1 \mathrm{ppb}$ and $-330 \mathrm{mHZ}$, respectively. The near identical $J$ and $\delta$ values resulting from the PERCH- and CT-based analyses indicates suitability of CT for comprehensive spin analysis of NMR spectra.

Structure Elucidation of Compounds 3 and 4. Both compounds had the same molecular formula, $\mathrm{C}_{21} \mathrm{H}_{32} \mathrm{O}_{10}$, as determined by HRESIMS. The ${ }^{1} \mathrm{H}$ NMR spectra of 3 and 4 (Table 2) displayed the typical dt-like higher-order resonances of an aromatic $\mathrm{AA}^{\prime} \mathrm{XX}^{\prime}$ spin system at around $\delta 7.33$ and $\delta 7.20 \mathrm{ppm}$, as well as the hydrogen signals of an isopropyl group featuring a septet at around $\delta 2.88$ and two superimposable doublets at $\delta 1.23 \mathrm{ppm}$. These characteristic signals suggested that $\mathbf{3}$ and $\mathbf{4}$ are derivatives of 7, ${ }^{19}$ a cuminol glycoside with a single glucose moiety. Different from 7, the hydrogen signals in the $\delta 3.2-5.0 \mathrm{ppm}$ region indicated that both 3 and 4 contained disaccharide moieties. On the basis of comprehensive 1D (Table 2) and 2D NMR data (Figures S-17-19 and S23-25, Supporting Information), the sugar moieties were identified as $\alpha$ L-arabinopyranosyl-( $1 \rightarrow 6)-\beta$-D-glucopyranosyl in $\mathbf{3}$ and $\alpha$-L-arabinofuranosyl-( $1 \rightarrow 6)-\beta$-Dglucopyranosyl in 4, respectively. HMBC experiments (Figures S16 and S21, Supporting Information) confirmed the attachment of the disaccharide moieties at C-7 for both $\mathbf{3}$ and $\mathbf{4}$. Hence, 3 and 4 were determined as cuminyl $\alpha$-L-arabinopyranosyl-( $1 \rightarrow 6)-\beta$-D-glucopyranoside and cuminyl $\alpha$-L-arabinofuranosyl- $(1 \rightarrow 6)-\beta$-D-glucopyranoside, respectively. This is the first report of cuminol glycosides $(\mathbf{3}, \mathbf{4}$, and $\mathbf{7})$ from the genus Rhodiola.

QM-HiFSA enabled the identification of all couplings, including long-range couplings. For example, the H-1" resonance in $\mathbf{4}$ appeared as a broad doublet that made it difficult to designate its multiplicity by visual spectral interpretation. The QM-HiFSA method (Table 1) revealed its actual multiplicity as a dd with a ${ }^{3} J$ coupling of $1.53 \mathrm{~Hz}$ with $\mathrm{H}-2^{\prime \prime}$ and a ${ }^{4} J$ long-range coupling of 0.58 with H-3". Moreover, QM-HiFSA established the long-range benzylic couplings ${ }^{8,20}$ within $\mathbf{3}$ and $\mathbf{4}$ as shown in Figure 8.

Since biological activity research of the monoterpene glycosides require further study and residual complexity could result in the misassignment of biological activity, ${ }^{21}$ therefore, the purity 
of all four new isolates was determined using the 100\% qHNMR method (Table S-1, Supporting Information), ${ }^{22}$ confirming the suitability of isolates for QM-based spectral analysis and biological follow-up studies.

\section{- CONCLUSION}

In addition to two known Rhodiola characteristic (-)-myrtenol glycosides (5 and 6) and one known cuminol glycoside (7), four new (+)-myrtenol cuminol glycosides (1/2 and 3/4, respectively) were isolated and characterized. This is the first report of myrtenol glycosides with enantiomeric aglycones and of cuminol glycosides in the genus Rhodiola. Concerning the wide use of $R$. rosea as an adaptogenic dietary supplement, the (+)-myrtenol glycosides (1 and 2 ) and cuminol glycosides $(\mathbf{3}, \mathbf{4}$, and 7) might have potential to serve as the new marker compounds, at least for chemotaxonomic standardization.

Given the complexity of the ${ }^{1} \mathrm{H}$ NMR signals, HiFSA-based spin-spin coupling analysis was applied to facilitate the elucidation and distinction of these structurally near-identical parts of compounds. This is the first report of precisely matched simulated and observed NMR spectra for the characterization of cyclic monoterpene glycosides. Detailed QM-HiFSA-based evaluation of both the sugar moieties as well as the aglycone portions of 1-4 provides a blueprint for future rapid dereplication and identification of analogous monoterpene glycosides that likely occur in $R$. rosea and other organisms. Moreover, the precision of the QM-based interpretation enables advanced qNMR assays for future botanical standardization of Rhodiola botanicals, as well as advances the purity analysis of glycosides via full resolution of the strong peak overlap in the range of the stereoisomeric ${ }^{1} \mathrm{H}$ NMR sugar resonances.

\section{EXPERIMENTAL SECTION}

General. Optical rotations at the sodium D line $(589 \mathrm{~nm})$ were measured with a PerkinElmer 241 digital polarimeter (Waltham, MA, USA) using a quartz cell with a path length of $100 \mathrm{~mm}$ in MeOH. NMR experiments were performed on a Jeol Resonance Inc. JNMR-ECZ400/L1 (Akishima, Tokyo, Japan) $400 \mathrm{MHz}$ NMR spectrometer. The instrument was equipped with a 5 mm $400 \mathrm{MHz}$ broadband Z-gradient high-resolution SuperCool NMR probe with liquid nitrogen loop cooling system (operating temperature $<85 \mathrm{~K}$ ). The QM-HiFSA calculations were carried out 
using PERCH NMR spin simulation software (v.2010.1, PERCH Solutions, Ltd., Kuopio, Finland). CT is currently in beta version for testing and an active license is available by contacting ct@nmrsolutions.fi. The 3D models were constructed using Chem 3D Pro (v. 18.1), and the structures were energy minimized using the MM2 module. HRESIMS analyses were carried out using a Waters 2695 (Milford, MA, USA) solvent delivery system connected to a Waters SYNAPT quadrupole/time-of-flight mass spectrometer. Semipreparative HPLC was performed with a YMCODS AQ semi-preparative column $(10 \times 250 \mathrm{~mm}, 5 \mu \mathrm{m})$ on a Waters 600 Delta system using $\mathrm{MeOH}-\mathrm{H}_{2} \mathrm{O}$ or $\mathrm{MeCN}-\mathrm{H}_{2} \mathrm{O}$ as the mobile phase at a flow rate of $3 \mathrm{~mL} / \mathrm{min}$. Visualization of the developed TLC plates were under UV light (254 and $365 \mathrm{~nm}$ ) and then after spraying the plates with a solution using vanillin/ $\mathrm{H}_{2} \mathrm{SO}_{4}$ (general purpose reagent). CPC separations were performed on a SCPE-250 centrifugal partition chromatography (CPC) extractor from Gilson Inc (Middleton, WI, USA). Solvents and reagents were purchased from Thermo Fisher Scientific (Hanover Park, IL, USA) and Sigma Aldrich (St. Louis, MO, USA). HPLC grade solvents were purchased from Sigma Aldrich and methanol- $d_{4}(99.8$ atom \% D) was purchased from Cambridge Isotope Laboratories Inc. (Andover, MA, USA). The samples were weighed with a Mettler Toledo XS105 Dual Range analytical balance. A Pressure-Lok gas syringe (Baton Rouge, LA, USA) was used for volumetric NMR sample preparation. TLC was performed on Alugram precoated $0.2 \mathrm{~mm}$ thick silica gel G/UV254 10 x $20 \mathrm{~cm}$ aluminum plates, Macherey-Nagel GmbH \& Co. (Düren, Germany). Syringe filters (CHROMAFIL Xtra PTFE-20/13, pore size: $0.20 \mu \mathrm{m}, 13 \mathrm{~mm}$ diameter) were used for CPC and HPLC sample filtration.

Plant Material. The material (UIC/NIH Botanical Center code BC 872) was from Rhodiola rosea plants cultivated at the University of Alaska Experimental Farm near Palmer, AK. The original plants were from Norway, and their seeds were sourced from Arrgo, Alta., Canada (61 34.189' N 149 15.336 W). Collection vouchers are deposited in the University of Illinois Herbarium under DS16452-DS16460.

Extraction and Isolation. The pulverized rhizomes/roots $(2.75 \mathrm{~kg})$ were defatted by hexane and dichloromethane successively, then extracted with distilled methanol at room temperature four times ( 4 x $6 \mathrm{~L}$ ) to afford the crude extract (680 g, semi-dry). The crude extracts ( $370 \mathrm{~g}$, semi-dry) were dissolved in $\mathrm{H}_{2} \mathrm{O}$ then partitioned with the mixture of $\mathrm{CHCl}_{3} / n-\mathrm{BuOH}(1: 4)$ to remove most of proanthocyanidins (PACs). The upper phase (97 g, non-PAC portion) was chromatographed over an HP-20 column, eluted with a gradient of $\mathrm{H}_{2} \mathrm{O} / \mathrm{MeOH}$ to afford $100 \% \mathrm{H}_{2} \mathrm{O}, 30 \% \mathrm{MeOH}$, 
50\% $\mathrm{MeOH}, 70 \% \mathrm{MeOH}$, and 100\% $\mathrm{MeOH}$ five fractions (Fr.1-Fr.5), respectively. Fr.4 was fractionated by CPC ( $264 \mathrm{~mL}$ rotor, $\mathrm{S}_{\mathrm{f}}=0.54$, flow rate $25 \mathrm{~mL} / \mathrm{min}, 2500 \mathrm{rpm}$ ) into five fractions (Fr.4a-Fr.4e) using the $\mathrm{CHCl}_{3}-\mathrm{MeOH}-\mathrm{H}_{2} \mathrm{O}$ (ChMWat) 9:7:3 solvent system, with the lower phase as a mobile phase (descending mode). Fr.4a was further fractionated by CPC into five fractions (Fr.4aa-Fr.4ae) with ChMWat 10:5:5 in descending mode $\left(S_{\mathrm{f}}=0.73\right)$. Semiprep-HPLC of Fr.4ab was then carried out with 30\% MeCN isocratic elution to afford three fractions (Fr.4ab1Fr.4ab3). Fr.4ab2 was purified on semiprep-HPLC (55\% MeOH) to furnish compound 7 (5.4 mg, $t_{\mathrm{R}}=13.7 \mathrm{~min}$ ) and other three fractions (Fr.4ab2a, Fr.4ab2c, and Fr.4ab2d). Compounds 2 (7.5 mg, $\left.t_{\mathrm{R}}=39.4 \mathrm{~min}\right)$ and $\mathbf{6}\left(1.6 \mathrm{mg}, t_{\mathrm{R}}=41.4 \mathrm{~min}\right)$ were isolated from Fr.4ab2d using semiprep-HPLC $(22 \% \mathrm{MeCN})$. Fr.4ad was subjected to prep-HPLC (52\% MeOH) to afford four fractions (Fr.4ad1.4ad4. Fr.4ad1 was further purified by prep-HPLC $(28 \% \mathrm{MeCN})$ to yield five fractions (Fr.4ad1a4ad1e). Compounds $3\left(47.1 \mathrm{mg}, t_{\mathrm{R}}=33.8 \mathrm{~min}\right)$ and $\mathbf{4}\left(4.2 \mathrm{mg}, t_{\mathrm{R}}=32.1 \mathrm{~min}\right)$ were obtained from Fr.4ad1c through prep-HPLC (35\% MeOH). Separation of Fr.4ad2 through HPLC (50\% MeOH) gave $\mathbf{1}\left(2.5 \mathrm{mg}, t_{\mathrm{R}}=47.2 \mathrm{~min}\right)$ and $\mathbf{5}\left(1.4 \mathrm{mg}, t_{\mathrm{R}}=49.4 \mathrm{~min}\right)$

(+)-Myrtenyl $\alpha$-L-arabinopyranosyl-( $1 \rightarrow 6)-\beta$-D-glucopyranoside (1): colorless solid; NMR (400 MHz, $\mathrm{CD}_{3} \mathrm{OD}$ ) see Table 2; HRESIMS m/z $469.2042\left[\mathrm{M}+\mathrm{Na}^{+}\right.$, calcd for $\mathrm{C}_{21} \mathrm{H}_{34} \mathrm{O}_{10} \mathrm{Na}$ (-1.7 ppm), 469.2050.

(+)-Myrtenyl $\beta$-D-glucopyranoside (2): colorless gum; NMR (400 MHz, $\mathrm{CD}_{3} \mathrm{OD}$ ) see Table 2; HRESIMS m/z 359.1693 [M + HCOO]', calcd for $\mathrm{C}_{17} \mathrm{H}_{27} \mathrm{O}_{8}(-3.6 \mathrm{ppm}), 359.1706$.

Cuminyl $\alpha$-L-arabinopyranosyl-( $(\rightarrow 6)-\beta$-D-glucopyranoside (3): colorless solid; NMR (400 $\left.\mathrm{MHz}, \mathrm{CD}_{3} \mathrm{OD}\right)$ see Table 2; HRESIMS m/z 443.1918 [M - H] $]^{-}$, calcd for $\mathrm{C}_{21} \mathrm{H}_{31} \mathrm{O}_{10}(0.2 \mathrm{ppm})$, 443.1917.

Cuminyl $\alpha$-L-arabinofuranosyl-( $1 \rightarrow 6)-\beta$-D-glucopyranoside (4): colorless solid; NMR (400 $\mathrm{MHz}, \mathrm{CD}_{3} \mathrm{OD}$ ) see Table 2; HRESIMS m/z 443.1926 [M - H]', calcd for $\mathrm{C}_{21} \mathrm{H}_{31} \mathrm{O}_{10}$ (2.0 ppm), 443.1917.

Acquisition of qHNMR Spectra. Samples were dissolved in $200 \mu \mathrm{L}$ of methanol- $d_{4}$ then transferred into $3 \mathrm{~mm}$ NMR tubes (Landisville, NJ, USA). All NMR experiments were performed at $298 \mathrm{~K}\left(25^{\circ} \mathrm{C}\right)$ using standard Jeol pulse sequences. Chemical shifts $(\delta)$ are expressed in ppm with reference to the residual solvent signals (3.3100 ppm for ${ }^{1} \mathrm{H}$ and $49.0000 \mathrm{ppm}$ for ${ }^{13} \mathrm{C}$ ). The qHNMR spectra were acquired using standard qHNMR parameters, ${ }^{23}$ including a relaxation delay of $60 \mathrm{~s}, 46$ receiver gain, and a $90^{\circ}$ flip angle. NMR data were processed and analyzed using 
Mestrenova 12.0.4 software from Mestrelab Research S.L. (Santiago de Compostela, Spain). For qHNMR analysis, the following processing scheme was used: a mild Lorentzian-to-Gaussian window function (line broadening $=-0.3 \mathrm{~Hz}$, Gaussian factor $=0.05$ ) was applied, followed by zero filling to $256 \mathrm{k}$ acquired data points before Fourier transformation. After manual phasing, a fifth-order polynomial baseline correction was applied.

Enzymatic Hydrolysis. Enzymatic hydrolysis procedures were carried out according to the previously reported protocol with modifications. ${ }^{24}$ Compounds $\mathbf{1}(2.7 \mathrm{mg})$ and $\mathbf{3}(2.8 \mathrm{mg})$ were dissolved in $4 \mathrm{~mL}$ water with snailase ( $c a .14 \mathrm{mg}$ ) at $40{ }^{\circ} \mathrm{C}$ for $24 \mathrm{~h}$, respectively. The solution was then extracted with EtOAc $(4 \times 4 \mathrm{~mL})$. The aqueous phase was concentrated under reduced pressure to afford a residue, which was purified by silica gel open column eluting with $\mathrm{CH}_{3} \mathrm{CN}$ $\mathrm{H}_{2} \mathrm{O}$ (8:1) to afford sugar mixture of $1.36 \mathrm{mg}$ (from 1) and $1.09 \mathrm{mg}$ (from 3), respectively. The two sugar mixtures exhibited identical ${ }^{1} \mathrm{H}$ NMR spectra with that of an authentic mixture of Larabinose and D-glucose (Figure S-27, Supporting Information). The four theoretical possibilities of sugar combinations and their corresponding specific rotation values are as follows: L-ara/D-glc (+155.7), D-ara/L-glc (-155.7), D-ara/D-glc (-50.3), and L-ara/L-glc (50.3). The $[\alpha]_{\mathrm{D}}^{20}$ values $\left(+138.3 c 0.091, \mathrm{H}_{2} \mathrm{O}\right.$ and $\left.+160.5 c 0.073, \mathrm{H}_{2} \mathrm{O}\right)$ observed in the present study are consistent with that of the authentic mixture of L-arabinose and D-glucose in a 1:1 ratio $\left(+155.4 c 0.241, \mathrm{H}_{2} \mathrm{O}\right)$.

\section{aSSOCIATED CONTENT}

\section{Supporting Information}

NMR data for compounds $1-4\left({ }^{1} \mathrm{H},{ }^{13} \mathrm{C}, \mathrm{COSY}, \mathrm{HSQC}, \mathrm{HMBC}\right.$, and NOESY). This material is available free of charge via the Internet at http://pubs.acs.org. The original NMR data (FIDs) of the spectra in the figures and tables are made available at DOI: https://doi.org/10.7910/DVN/Y0DH49.

\section{口 AUTHOR INFORMATION}

\section{Corresponding Author}

*Tel: +1 (312) 355-1949. Fax: +1 (312) 355-2693. E-mail: gfp@ uic.edu. 


\section{ACKNOWLEDGMENT}

This study was supported by grants P50AT000155 and U41AT008706 from the Office of Dietary Supplements (ODS) and the National Center for Complementary and Integrative Health (NCCIH) of the NIH. The authors wish to thank the Alaska Rhodiola growers, especially. Dr. Petra Illig of AK Roseroot, as well as the Anchor Point Nursery, for their commitment to sustainability of Rhodiola plant resources and support of our collection trips.

\section{REFERENCES}

(1) Panossian, A.; Wikman, G.; Sarris, J. Phytomedicine 2010, 17, 481-493.

DOI:10.1016/j.phymed.2010.02.002.

(2) Marchev, A. S.; Dinkova-Kostova, A. T.; György, Z.; Mirmazloum, I.; Aneva, I. Y.; Georgiev, M. I. Phytochem. Rev. 2016, 15, 515-536. DOI:10.1007/s11101-016-9453-5.

(3) Tao, H.; Wu, X.; Cao, J.; Peng, Y.; Wang, A.; Pei, J.; Xiao, J.; Wang, S.; Wang, Y. Med. Res. Rev. 2019, 39, 1779-1850. DOI:10.1002/med.21564.

(4) Saratikov, A. S. Tomsk University Publisher 1974, 158.

(5) van Diermen, D.; Marston, A.; Bravo, J.; Reist, M.; Carrupt, P.-A.; Hostettmann, K. J. Ethnopharmacol. 2009, 122, 397-401. DOI:10.1016/j.jep.2009.01.007.

(6) Liu, Y.; Chen, S.-N.; McAlpine, J. B.; Klein, L. L.; Friesen, J. B.; Lankin, D. C.; Pauli, G. F. J. Nat. Prod. 2014, 77, 611-617. DOI:10.1021/np400874z.

(7) Pauli, G. F.; Pro, S. M.; Friesen, J. B. J. Nat. Prod. 2008, 71, 1489-1508. DOI:10.1021/np800144q.

(8) Nam, J.-W.; Phansalkar, R. S.; Lankin, D. C.; Bisson, J.; McAlpine, J. B.; Leme, A. A.; Vidal, C. M. P.; Ramirez, B.; Niemitz, M.; Bedran-Russo, A.; Chen, S.-N.; Pauli, G. F. J. Org. Chem. 2015, 80, 7495-7507. DOI:10.1021/acs.joc.5b01082.

(9) Pauli, G. F.; Chen, S.-N.; Lankin, D. C.; Bisson, J.; Case, R. J.; Chadwick, L. R.; Gödecke, T.; Inui, T.; Krunic, A.; Jaki, B. U.; McAlpine, J. B.;Mo, S.; Napolitano, J. G.; Orjala, J.; Lehtivarjo, J.; Korhonen, S.-P.; Niemitz, M. J. Nat. Prod. 2014, 77, 1473-1487. DOI:10.1021/np5002384.

(10) Nakamura, S.; Li, X.; Matsuda, H.; Ninomiya, K.; Morikawa, T.; Yamaguti, K.; Yoshikawa, M. Chem. Pharm. Bull. 1997, 45, 1498-1503. DOI:10.1248/cpb.55.1505.

(11) Laatikainen, R.; Niemitz, M.; Weber, U.; Sundelin, J.; Hassinen, T.; Vepsäläinen, J. J. Magn. Reson. A 1996, 120, 1-10. DOI:10.1006/jmra.1996.0094.

(12) Yoshikawa, M.; Shimada, H.; Horikawa, S.; Murakami, T.; Shimoda, H.; Yamahara, J.; Matsuda, H. Chem. Pharm. Bull. 1997, 45, 1498-1503. DOI:10.1248/cpb.45.1498.

(13) Napolitano, J. G.; Gödecke, T.; Rodríguez-Brasco, M. F.; Jaki, B. U.; Chen, S.-N.; Lankin, D. C.; Pauli, G. F. J. Nat. Prod. 2012, 75, 238-248. DOI:10.1021/np200949v.

(14) Pauli, G. F.; Niemitz, M.; Bisson, J.; Lodewyk, M. W.; Soldi, C.; Shaw, J. T.; Tantillo, D. J.; Saya, J. M.; Vos, K.; Kleinnijenhuis, R. A.; Hiemstra, H.; Chen, S.-N.; McAlpine, J. B.; Lankin, D. C.; Friesen, J. B. J. Org. Chem. 2016, 81, 878-889. DOI:10.1021/acs.joc.5b02456.

(15) Gamba, A.; Mondelli, R. Tetrahedron Lett. 1971, 12, 2133-2138. DOI:10.1016/S00404039(01)96801-7.

(16) Choules, M. P.; Bisson, J.; Gao, W.; Lankin, D. C.; McAlpine, J. B.; Niemitz, M.; Jaki, B. U.; Franzblau, S. G.; Pauli, G. F. J. Org. Chem. 2019, 84, 3055-3073. DOI:10.1021/acs.joc.8b02704.

(17) Cosmic Truth https://ctb.nmrsolutions.fi/ (accessed Jan 31, 2020).

(18) Website ChemAdder software: http://www.chemadder.com/index.html (accessed Jan 31, 2020). 
(19) Fujita, T.; Ohira, K.; Miyatake, K.; Nakano, Y.; Nakayama, M. Chem. Pharm. Bull. 1995, 43, 920926. DOI:10.1248/cpb.43.920.

(20) Barfield, M.; Chakrabarti, B. Chem. Rev. 1969, 69, 757-778. DOI:10.1021/cr60262a001.

(21) Choules, M. P.; Klein, L. L.; Lankin, D. C.; McAlpine, J. B.; Cho, S.-H.; Cheng, J.; Lee, H.; Suh, J.W.; Jaki, B. U.; Franzblau, S. G.; Pauli, G. F. J. Org. Chem. 2018, 83, 6664-6672. DOI:10.1021/acs.joc.8b00988.

(22) Pauli, G. F.; Chen, S.-N.; Simmler, C.; Lankin, D. C.; Gödecke, T.; Jaki, B. U.; Friesen, J. B.; McAlpine, J. B.; Napolitano, J. G. J. Med. Chem. 2014, 57, 9220-9231. DOI:10.1021/jm500734a.

(23) Pauli, G. F.; Jaki, B. U.; Lankin, D. C. J. Nat. Prod. 2007, 70, 589-595. DOI:10.1021/np060535r.

(24) Jiang, Y.-P.; Liu, Y.-F.; Guo, Q.-L.; Shi, J.-G. J. Asian Nat. Prod. Res. 2015, 17, 1166-1179. DOI:10.1080/10286020.2015.1112797. 
Table 1. Summary of the QM-HiFSA Analysis of the ${ }^{1} \mathbf{H},{ }^{1} \mathrm{H} J$ Coupling Constants of the Sugar Moieties in 1-4

\begin{tabular}{|c|c|c|c|c|c|c|c|c|c|c|c|c|c|c|c|c|}
\hline \multirow[t]{2}{*}{$\operatorname{glc} p(\mathbf{1})$} & \multirow[t]{2}{*}{ multiplicity } & \multicolumn{7}{|c|}{ iterated $J$ coupling constants } & \multirow[t]{2}{*}{$\operatorname{arap}(\mathbf{1})$} & \multirow[t]{2}{*}{ multiplicity } & \multicolumn{6}{|c|}{ iterated $J$ coupling constants } \\
\hline & & $\mathrm{H}-\mathrm{1}^{\prime}$ & H-2' & H-3' & H-4' & H-5' & H-6'a & $H-6^{\prime} b$ & & & H-1" & H-2" & H-3" & H-4" & H-5"a & $\mathrm{H}-5 " \mathrm{~b}$ \\
\hline H-1' & $\mathrm{d}$ & & 7.87 & & & & & & H-1" & $\mathrm{d}$ & & 6.86 & & & & \\
\hline $\mathrm{H}-2^{\prime *}$ & $\mathrm{dd}$ & 7.87 & & 9.25 & & & & & H-2" & dd & 6.86 & & 8.75 & & & \\
\hline $\mathrm{H}-3^{\prime *}$ & ddd & & 9.25 & & 8.70 & & & & H-3" & dd & & 8.75 & & 3.47 & & \\
\hline $\mathrm{H}-4^{\prime} *$ & dd & & & 8.70 & & 9.67 & & & H-4" & ddd & & & 3.47 & & 3.25 & 1.80 \\
\hline $\mathrm{H}-5^{\prime *}$ & ddd & & & & 9.67 & & 2.35 & 5.62 & H-5"a & dd & & & & 3.25 & & -12.46 \\
\hline H-6'a & dd & & & & & 2.35 & & -11.39 & $\mathrm{H}-5 " \mathrm{~b}$ & $\mathrm{dd}$ & & & & 1.80 & -12.46 & \\
\hline $\begin{array}{l}\text { H-6'b } \\
\text { glcp (2) }\end{array}$ & $\mathrm{dd}$ & & & & & 5.62 & -11.39 & & & & & & & & & \\
\hline H-1' & $\mathrm{d}$ & & 7.85 & & & & & & & & & & & & & \\
\hline H-2' & $\mathrm{dd}$ & 7.85 & & 9.26 & & & & & & & & & & & & \\
\hline H-3' & ddd & & 9.26 & & 9.02 & -0.33 & & & & & & & & & & \\
\hline H-4' & dd & & & 9.02 & & 9.79 & & & & & & & & & & \\
\hline H-5' & dddd & & & -0.33 & 9.79 & & 2.31 & 5.90 & & & & & & & & \\
\hline H-6'a & dd & & & & & 2.31 & & -11.92 & & & & & & & & \\
\hline H-6'b & $\mathrm{dd}$ & & & & & 5.90 & -11.92 & & & & & & & & & \\
\hline glcp (3) & & & & & & & & & $\operatorname{arap}(\mathbf{3})$ & & & & & & & \\
\hline H-1' & $\mathrm{d}$ & & 7.85 & & & & & & H-1" & $\mathrm{d}$ & & 6.86 & & & & \\
\hline $\mathrm{H}-2^{\prime *}$ & dd & 7.85 & & 9.21 & & & & & H-2" & dd & 6.86 & & 8.80 & & & \\
\hline $\mathrm{H}-3^{\prime *}$ & dd & & 9.21 & & 9.14 & & & & H-3" & dd & & 8.80 & & 3.50 & & \\
\hline $\mathrm{H}-4^{\prime *}$ & $\mathrm{dd}$ & & & 9.14 & & 9.68 & & & H-4" & ddd & & & 3.50 & & 3.20 & 1.81 \\
\hline H-5'* & ddd & & & & 9.68 & & 2.22 & 5.90 & H-5"a & $\mathrm{dd}$ & & & & 3.20 & & -12.49 \\
\hline H-6'a & dd & & & & & 2.22 & & -11.51 & H-5"b & $\mathrm{dd}$ & & & & 1.81 & -12.49 & \\
\hline $\begin{array}{l}\text { H-6'b } \\
\text { glcp (4) }\end{array}$ & $\mathrm{dd}$ & & & & & 5.90 & -11.51 & & $\operatorname{araf}(\mathbf{4})$ & & & & & & & \\
\hline H-1' & d & & 7.85 & & & & & & H-1" & dd & & 1.53 & 0.58 & & & \\
\hline H-2' & $\mathrm{dd}$ & 7.85 & & 9.28 & & & & & H-2" & dd & 1.53 & & 3.36 & & & \\
\hline H-3' & $\mathrm{dd}$ & & 9.28 & & 9.07 & & & & H-3" & ddd & 0.58 & 3.36 & & 5.98 & & \\
\hline H-4' & dd & & & 9.07 & & 9.53 & & & H-4" & ddd & & & 5.98 & & 3.30 & 5.35 \\
\hline H-5' & ddd & & & & 9.53 & & 2.38 & 6.14 & H-5"a & dd & & & & 3.30 & & -11.87 \\
\hline H-6'a & dd & & & & & 2.38 & & -11.18 & H-5"b & dd & & & & 5.35 & -11.87 & \\
\hline H-6'b & dd & & & & & 6.14 & -11.18 & & & & & & & & & \\
\hline
\end{tabular}

*Signal exhibits higher order effects; the multiplicities given are under first order assumptions, but represent distorted "multiplets". 
Table 2. The ${ }^{1} \mathrm{H}$ and ${ }^{13} \mathrm{C}$ NMR Data of $1-4^{a, b}$

\begin{tabular}{|c|c|c|c|c|c|c|c|c|}
\hline \multirow{2}{*}{ position } & \multicolumn{2}{|l|}{1} & \multicolumn{2}{|l|}{2} & \multicolumn{2}{|l|}{3} & \multicolumn{2}{|l|}{4} \\
\hline & $\delta_{\mathrm{H}}(J$ in $\mathrm{HZ})$ & $\delta_{\mathrm{C}}$ & $\delta_{\mathrm{H}}(J$ in $\mathrm{HZ})$ & $\delta_{\mathrm{C}}$ & $\delta_{\mathrm{H}}(J$ in HZ) & $\delta_{\mathrm{C}}$ & $\delta_{\mathrm{H}}(J$ in $\mathrm{HZ})$ & $\delta_{\mathrm{C}}$ \\
\hline 1 & $\begin{array}{l}2.2453, \text { td-like }(5.84,5.42,-1.43,-0.21,- \\
0.20)\end{array}$ & 44.51 & $\begin{array}{l}2.2447, \text { td-like }(5.86,5.42,-1.40,-0.22,- \\
0.20)\end{array}$ & 44.47 & & 136.43 & & 136.21 \\
\hline 2 & & 145.92 & & 146.06 & $\begin{array}{l}\text { 7.3388, dt-like }(7.87,1.88,- \\
0.57,0.57,-0.31,0.28)\end{array}$ & 129.46 & $\begin{array}{l}\text { 7.3393, dt-like }(7.90,2.01,- \\
0.52,0.51,-0.47,0.27)\end{array}$ & 129.58 \\
\hline 3 & $\begin{array}{l}5.5981 \text {, dddddd }(3.09,2.91,-1.67,-1.43 \text {, } \\
1.35,-1.21)\end{array}$ & 121.75 & $\begin{array}{l}5.5840, \text { dddddd }(3.06,2.87,-1.73,-1.40 \\
1.33,-1.13)\end{array}$ & 121.58 & $\begin{array}{l}\text { 7.2044, dt-like }(7.87,1.85,0.57 \\
0.49,0.20,-0.18)\end{array}$ & 127.28 & $\begin{array}{l}\text { 7.2077, dt-like }(7.90,1.85,0.56 \\
0.51,-0.21,0.20)\end{array}$ & 127.29 \\
\hline $4 a$ & $\begin{array}{l}2.3296, \text { dddddd }(-17.83,3.09,2.88,1.89 \text {, } \\
1.47,0.48)\end{array}$ & 32.28 & $\begin{array}{l}2.3277 \text {, dddddd }(-17.78,3.06,2.92,1.87 \text {, } \\
1.42,0.45)\end{array}$ & 32.27 & & 149.65 & & 149.71 \\
\hline $4 \mathrm{~b}$ & $\begin{array}{l}2.2609, \text { ddddd }(-17.83,2.91,2.51,2.30,- \\
1.67)\end{array}$ & & $\begin{array}{l}2.2616, \text { ddddd }(-17.78,2.87,2.55,2.39,- \\
1.71)\end{array}$ & & & & & \\
\hline 5 & 2.0864, ddddd $(5.84,5.83,2.88,2.51,1.35)$ & 42.13 & 2.0881 , ddddd $(5.86,5.82,2.92,2.55,1.33)$ & 42.12 & $\begin{array}{l}\text { 7.2044, dt-like }(7.87,1.85,0.57 \\
0.49,0.20,-0.18)\end{array}$ & 127.28 & $\begin{array}{l}\text { 7.2077, dt-like }(7.90,1.85,0.51 \\
0.56,-0.21,0.20)\end{array}$ & 127.29 \\
\hline $6 \mathrm{a}$ & 2.4248, dddd $(-8.67,5.83,5.42,0.17)$ & 32.44 & 2.4256, dddd $(-8.66,5.82,5.42,0.19)$ & 32.42 & $\begin{array}{l}\text { 7.3388, dt-like }(7.87,1.88,- \\
0.57,0.57,0.28,-0.31)\end{array}$ & 129.46 & $\begin{array}{l}\text { 7.3393, dt-like }(7.90,2.01,0.51 \\
-0.52,-0.47,0.27)\end{array}$ & 129.58 \\
\hline $6 b$ & 1.1984, ddd (br d) $(-8.67,0.30,0.16)$ & & 1.1992, ddd (br d) $(-8.66,0.29,0.27)$ & & & & & \\
\hline $7 \mathrm{a}$ & & 38.93 & & 38.91 & $\begin{array}{l}4.8740, \text { ddd (br d) }(-11.51,0.49, \\
-0.31)\end{array}$ & 71.77 & $\begin{array}{l}4.8541, \text { ddd (br d) }(-11.29,0.56 \text {, } \\
-0.47)\end{array}$ & 71.74 \\
\hline $7 \mathrm{~b}$ & & & & & $\begin{array}{l}4.6302 \text {, ddd (br d) (-11.51, }-0.57 \text {, } \\
0.20)\end{array}$ & & $\begin{array}{l}\text { 4.6197, ddd (br d) }(-11.29,-0.52 \text {, } \\
0.20)\end{array}$ & \\
\hline 8 & 0.8529, ddd (br s) $(0.35,-0.21,0.16)$ & 21.40 & 0.8524, ddd (br s) $(0.38,0.27,-0.20)$ & 21.37 & 2.8862 , septet $(6.94,6.91,-0.24)$ & 35.17 & 2.8883 , septet $(6.93,6.92,0.27)$ & 35.17 \\
\hline 9 & $\begin{array}{l}1.3069 \text {, ddddd (br s) }(0.48,0.35,0.30,-0.20 \text {, } \\
0.17)\end{array}$ & 26.67 & $\begin{array}{l}\text { 1.3056, ddddd (br s) }(0.45,0.38,0.29,-0.22 \text {, } \\
0.19)\end{array}$ & 26.65 & $1.2344, \mathrm{~d}(6.94)$ & 24.46 & $1.2364, \mathrm{~d}(6.93)$ & 24.46 \\
\hline $10 \mathrm{a}$ & $4.1440, \operatorname{dddd}(-12.33,2.30,1.89,-1.67)$ & 72.67 & 4.1635, dddd $(-12.39,2.39,1.87,-1.73)$ & 72.46 & $1.2344, \mathrm{~d}(6.91)$ & 24.46 & $1.2362, \mathrm{~d}(6.92)$ & 24.46 \\
\hline $10 \mathrm{~b}$ & 4.0511, dddd $(-12.33,-1.67,1.47,-1.21)$ & & 4.0730, dddd $(-12.39,-1.71,1.42,-1.13)$, & & & & & \\
\hline 1 ' & $4.2659, \mathrm{~d}(7.87)$ & 102.77 & $4.2680, \mathrm{~d}(7.85)$ & 102.67 & $4.3489, \mathrm{~d}(7.85)$ & 103.21 & $4.3365, \mathrm{~d}(7.85)$ & 103.05 \\
\hline $2^{\prime}$ & 3.1946 , dd $(9.25,7.87)$ & 74.99 & $3.1924, \mathrm{dd}(9.26,7.85)$ & 75.04 & $3.2455, \mathrm{dd}(9.21,7.85)$ & 75.09 & $3.2315, \mathrm{dd}(9.28,7.85)$ & 75.10 \\
\hline 3' & 3.3309 , dd $(9.28,8.70)$ & 77.97 & 3.3341 , t-like $(9.26,9.02,-0.33)$ & 78.13 & 3.3407, t-like $(9.21,9.14)$ & 77.93 & $3.3328, \mathrm{dd}(9.28,9.07)$ & 77.98 \\
\hline $4^{\prime}$ & $3.3402, \mathrm{dd}(9.67,8.70)$ & 71.62 & 3.2816, t-like $(9.79,9.02)$ & 71.66 & 3.3518, t-like $(9.68,9.14)$ & 71.68 & $3.2975, \mathrm{dd}(9.53,9.07)$ & 71.99 \\
\hline 5 , & 3.4006 , ddd $(9.67,5.62,2.35)$ & 76.87 & 3.2231 , dddd $(9.79,5.90,2.31,-0.33)$ & 77.92 & 3.4484 , ddd $(9.68,5.90,2.22)$ & 76.99 & 3.4362 , ddd $(9.53,6.14,2.38)$ & 76.81 \\
\hline 6’a & $4.0842, \mathrm{dd}(-11.39,2.35)$ & 69.38 & $3.8622, \mathrm{dd}(-11.92,2.31)$ & 62.75 & $4.1185, \mathrm{dd}(-11.51,2.22)$ & 69.48 & $4.0528, \mathrm{dd}(-11.18,2.38)$ & 68.12 \\
\hline 6 'b & 3.7351 , dd $(-11.39,5.62)$ & & 3.6651 , dd $(-11.92,5.90)$ & & 3.7564 , dd $(-11.51,5.90)$ & & $3.6441, \mathrm{dd}(-11.18,6.14)$ & \\
\hline 1 ," & $4.3242, \mathrm{~d}(6.86)$ & 105.12 & & & $4.3472, \mathrm{~d}(6.86)$ & 105.21 & $5.0065, \mathrm{dd}(1.53,0.58)$ & 110.00 \\
\hline $2 "$ & $3.5945, \mathrm{dd}(8.75,6.86)$ & 72.36 & & & $3.6097, \mathrm{dd}(8.80,6.86)$ & 72.40 & $4.0334, \mathrm{dd}(3.36,1.53)$ & 83.29 \\
\hline $3^{\prime \prime}$ & $3.5292, \mathrm{dd}(8.75,3.47)$ & 74.19 & & & $3.5106,(8.80,3.50)$ & 74.20 & 3.8451 , ddd $(5.98,3.36,0.58)$ & 78.94 \\
\hline $4 "$ & 3.8082 , ddd $(3.47,3.25,1.80)$ & 69.46 & & & 3.7997 , ddd $(3.50,3.20,1.81)$ & 69.50 & 3.9992 , ddd $(5.98,5.35,3.30)$ & 85.85 \\
\hline 5 " a & $3.8681, \mathrm{dd}(-12.46,3.25)$ & 66.69 & & & 3.8675 , dd $(-12.49,3.20)$ & 66.73 & 3.7538, dd $(-11.87,3.30)$ & 63.07 \\
\hline 5 'b & $3.5400, \mathrm{dd}(-12.46,1.80)$ & & & & $3.5182, \mathrm{dd}(-12.49,1.81)$ & & $3.6539, \mathrm{dd}(-11.87,5.35)$ & \\
\hline
\end{tabular}

${ }^{a}$ The ${ }^{1} \mathrm{H}$ and ${ }^{13} \mathrm{C}$ NMR data were acquired in $\mathrm{CD}_{3} \mathrm{OD}$ at 400 and $100 \mathrm{MHz}$, respectively. ${ }^{b}$ The $\delta_{\mathrm{H}}$ (in ppm) and $J$

(in $\mathrm{Hz}$ ) values were determined by QM-HiFSA analysis. 


\section{Chemical Formulas}

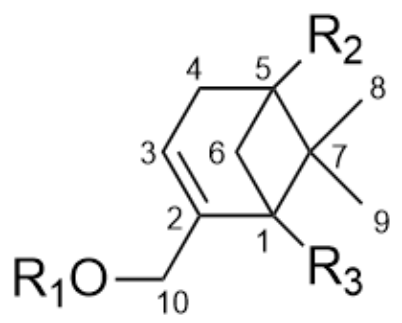

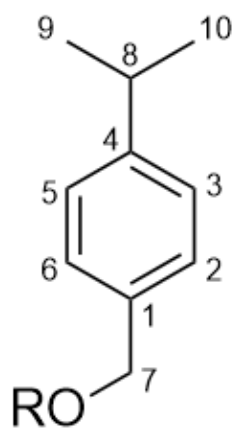

1: $\mathrm{R}_{1}=-\operatorname{glc}(p)^{6}$-ara $(p), \mathrm{R}_{2}=\mathrm{R}_{3}=\beta \mathrm{H} \quad 3: \mathrm{R}=-\operatorname{glc}(p)^{6}$-ara $(p)$

2: $\mathrm{R}_{1}=-\operatorname{glc}(p), \mathrm{R}_{2}=\mathrm{R}_{3}=\beta \mathrm{H}$

4: $\mathrm{R}=-\operatorname{glc}(p)^{6}$-ara $(f)$

5: $\mathrm{R}_{1}=-\operatorname{glc}(p)^{6}-\operatorname{ara}(p), \mathrm{R}_{2}=\mathrm{R}_{3}=\alpha \mathrm{H} \quad$ 7: $\mathrm{R}=-\operatorname{glc}(p)$

6: $\mathrm{R}_{1}=-\operatorname{glc}(p), \mathrm{R}_{2}=\mathrm{R}_{3}=\alpha \mathrm{H}$ 


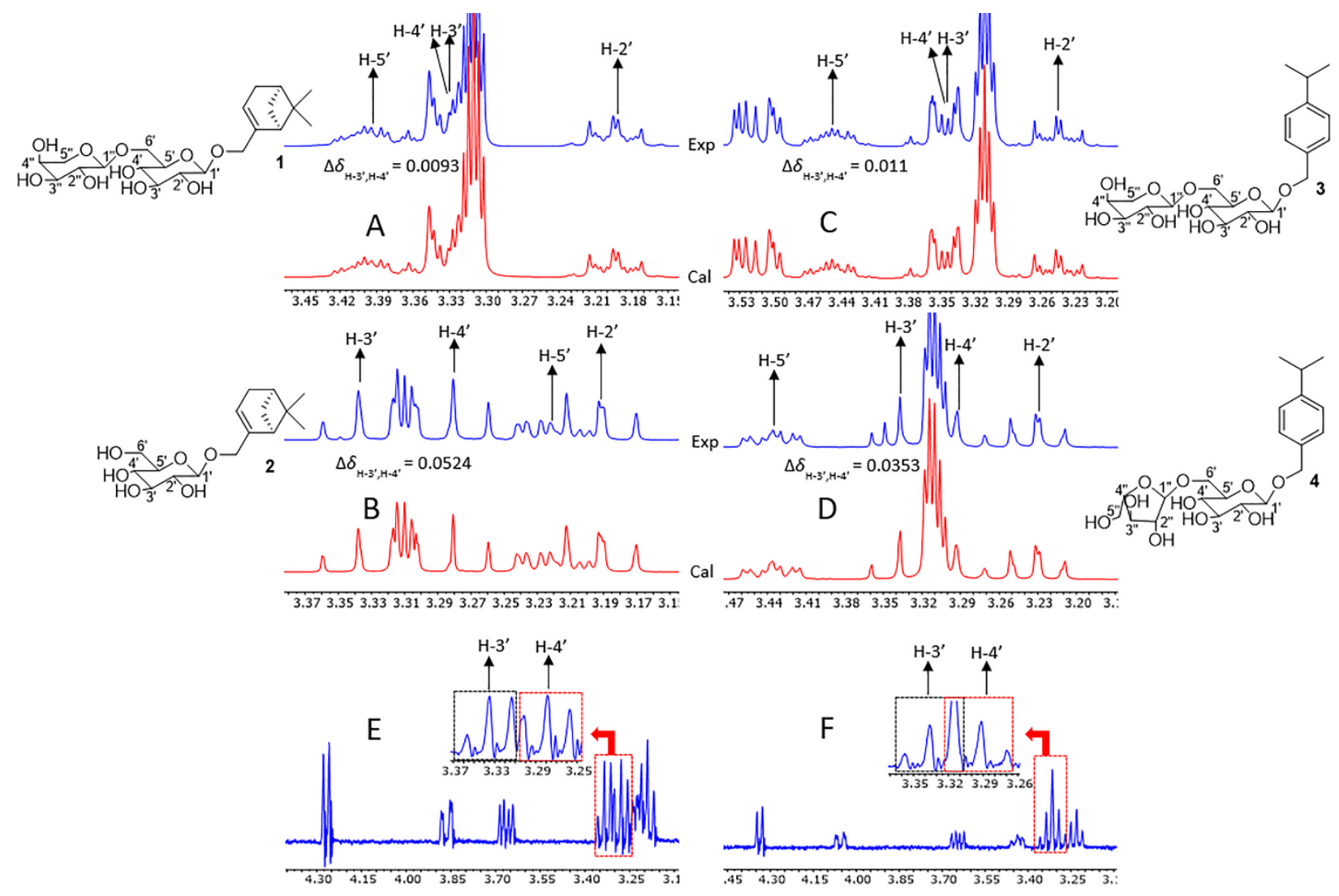

Figure 1. QM-HiFSA spin simulation analysis of the resonances of $\mathrm{H}-2{ }^{\prime}-\mathrm{H}-5$ ' of the glucose portions of 1-4 (A-D), as well as the 1D-TOCSY spectra of glucose in 2 (E) and $\mathbf{4}(\mathrm{F})$. The calculated spectra and experimental spectra $(400 \mathrm{MHz}, 298 \mathrm{~K})$ are shown in red and blue, respectively (* denotes impurity signals). 


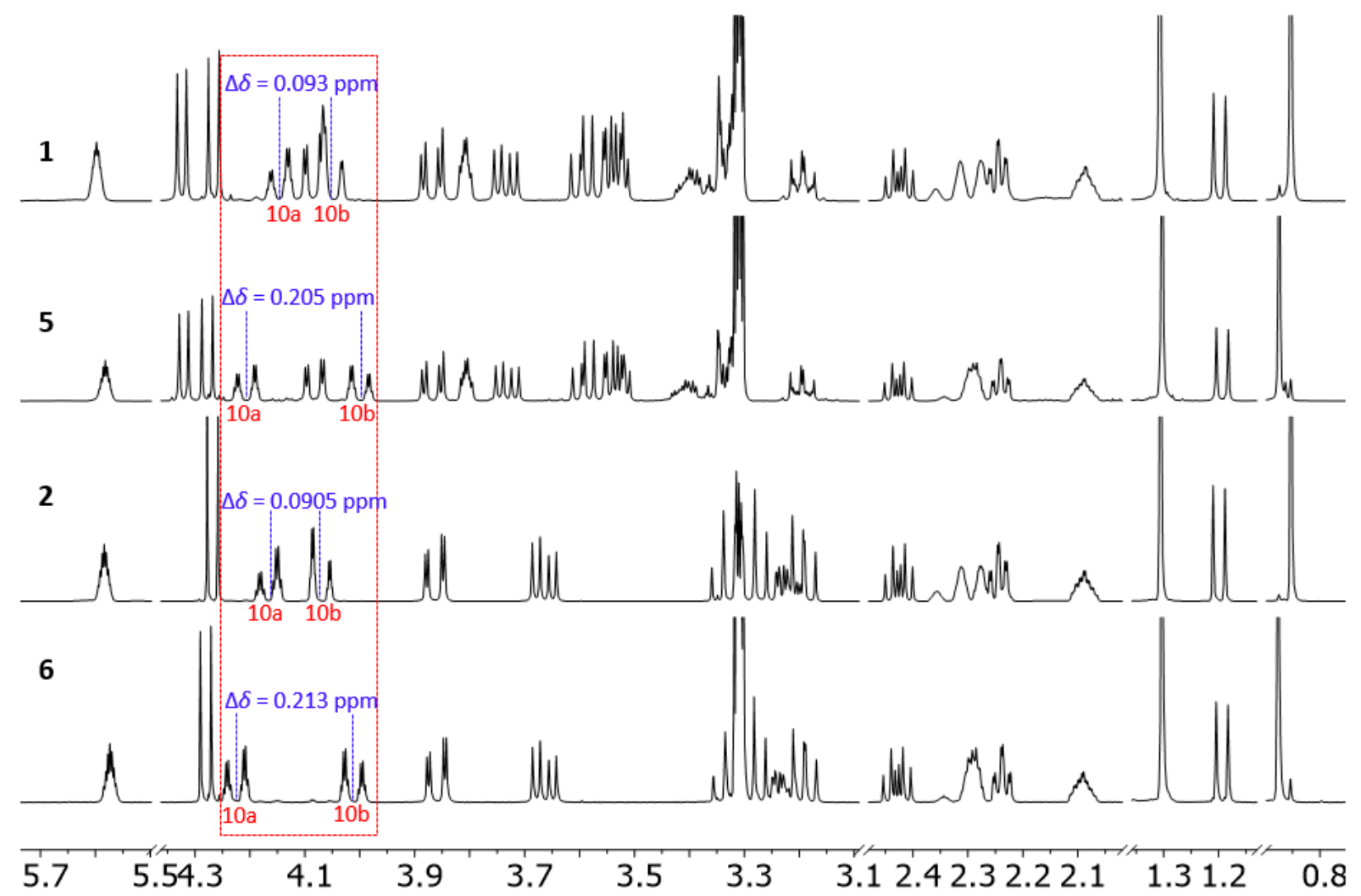

Figure 2. The importance of relative chemical shifts $(\Delta \delta)$ as indirect, but significant, structural evidence demonstrated for H-10a and $\mathrm{H}-10 \mathrm{~b}$ in $\mathbf{1 , 2}, \mathbf{5}$, and $\mathbf{6}$. 


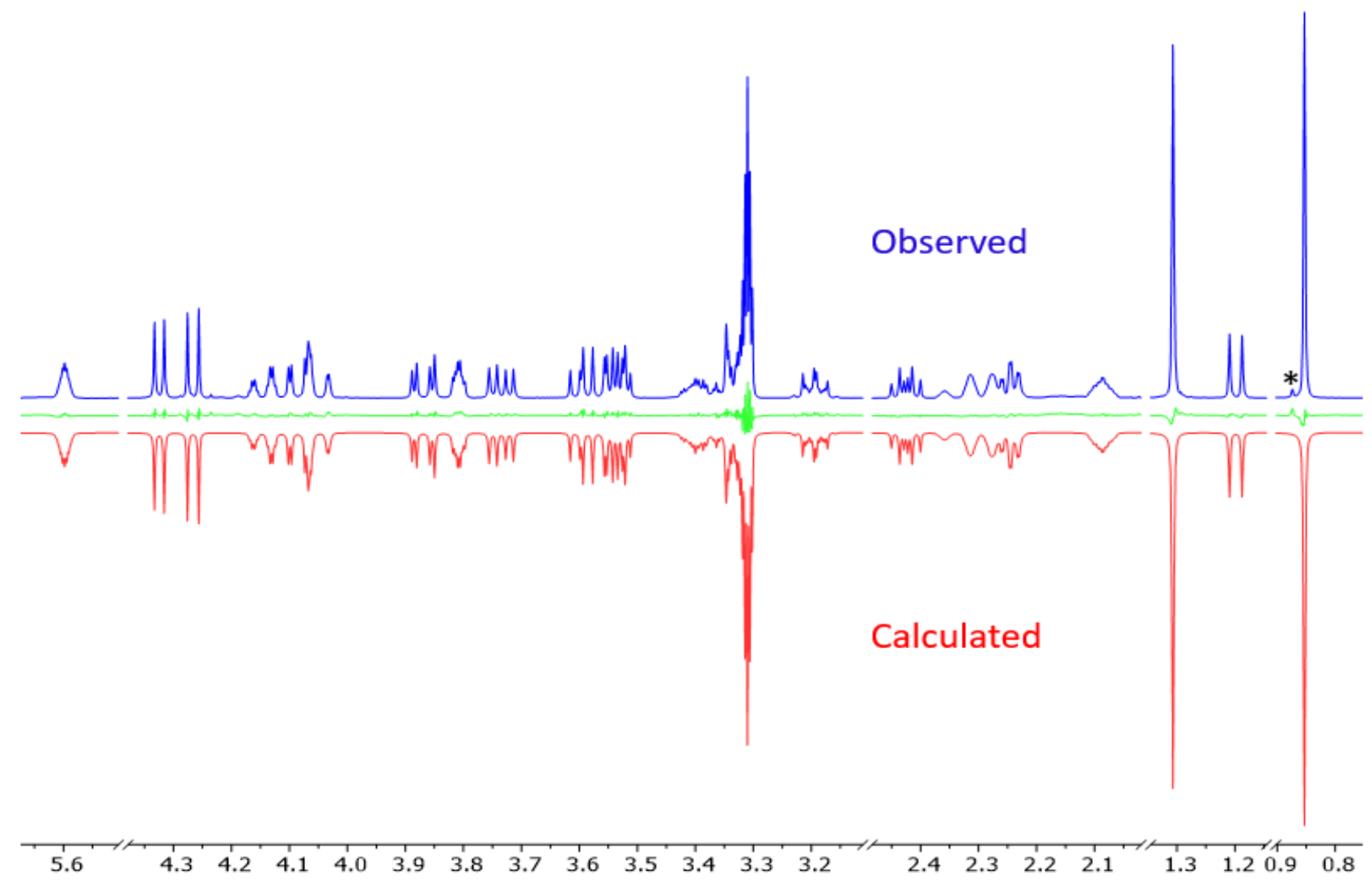

Figure 3. The ${ }^{1} \mathrm{H}$ NMR fingerprint of compound 1 generated using the PERCH iteration tool (final $\mathrm{RMS}=0.030$ ). Comparison of the observed (blue, obtained in $\mathrm{CD}_{3} \mathrm{OD}$ at $400 \mathrm{MHz}, 298 \mathrm{~K}$ ) and calculated (red) ${ }^{1} \mathrm{H}$ spectra, including residuals in green (* denotes an impurity signal). 


\begin{tabular}{|l|l|l|c|c|c|c|c|c|c|c|c|c|c|}
\hline $\boldsymbol{\delta} \mathbf{1}$ & $\mathbf{M}$ & $\mathrm{H}$ & $\mathrm{H}-\mathbf{1}$ & $\mathbf{H - 3}$ & H-4a & H-4b & H-5 & H-6a & H-6b & H-8 & H-9 & H-10a & H-10b \\
\hline 2.2453 & ddd(dd) & H-1 & & 4 & 5 & 5 & 4 & 3 & 3 & 4 & 4 & 4 & 4 \\
\hline 5.5981 & dddddd & H-3 & -1.43 & & 3 & 3 & 4 & 5 & 5 & 6 & 6 & 4 & 4 \\
\hline 2.3296 & ddddd(d) & H-4a & $\varnothing$ & 3.09 & & 2 & 3 & 4 & 4 & 5 & 5 & 5 & 5 \\
\hline 2.2609 & ddddd & H-4b & $\varnothing$ & 2.91 & -17.83 & & 3 & 4 & 4 & 5 & 5 & 5 & 5 \\
\hline 2.0864 & ddddd & H-5 & 5.84 & 1.35 & 2.88 & 2.51 & & 3 & 3 & 4 & 4 & 6 & 6 \\
\hline 2.4248 & ddd(d) & H-6a & 5.42 & $\varnothing$ & $\varnothing$ & $\varnothing$ & 5.83 & & 2 & 5 & 5 & 5 & 5 \\
\hline 1.1984 & d(dd) & H-6b & $\varnothing$ & $\varnothing$ & $\varnothing$ & $\varnothing$ & $\varnothing$ & -8.67 & & 5 & 5 & 5 & 5 \\
\hline 0.8529 & (ddd) & H-8 & -0.21 & $\varnothing$ & $\varnothing$ & $\varnothing$ & $\varnothing$ & $\varnothing$ & 0.16 & & 4 & 6 & 6 \\
\hline 1.3069 & (ddddd) & H-9 & -0.20 & $\varnothing$ & 0.48 & $\varnothing$ & $\varnothing$ & 0.17 & 0.30 & 0.35 & & 6 & 6 \\
\hline 4.1440 & dddd & H-10a & $\varnothing$ & -1.67 & 1.89 & 2.30 & $\varnothing$ & $\varnothing$ & $\varnothing$ & $\varnothing$ & $\varnothing$ & & 2 \\
\hline 4.0511 & dddd & H-10b & $\varnothing$ & -1.21 & 1.47 & -1.67 & $\varnothing$ & $\varnothing$ & $\varnothing$ & $\varnothing$ & $\varnothing$ & -12.33 & \\
\hline
\end{tabular}

Figure 4. The Quantum Interaction and Linkage Table (QuILT) summarizes the full $J$ correlation map the aglycone portion of $\mathbf{1}$ produced by QM-HiFSA based on the $400 \mathrm{MHz} 1 \mathrm{D}{ }^{1} \mathrm{H}$ NMR data. The number of bonds separating two coupled nuclei are color-coded: violet $={ }^{2} J$, blue $={ }^{3} J$, yellow $={ }^{4} \mathrm{~J}$, green $={ }^{5} \mathrm{~J}$, and pink $={ }^{6} \mathrm{~J}$. Multiplicities in parentheses are less than $\sim 1 \mathrm{~Hz}$. Couplings less than an absolute value of $0.10 \mathrm{~Hz}$ are given as " $\varnothing$ " rather than being reported as blank cells, which would wrongly imply them being unknown or undetermined. 


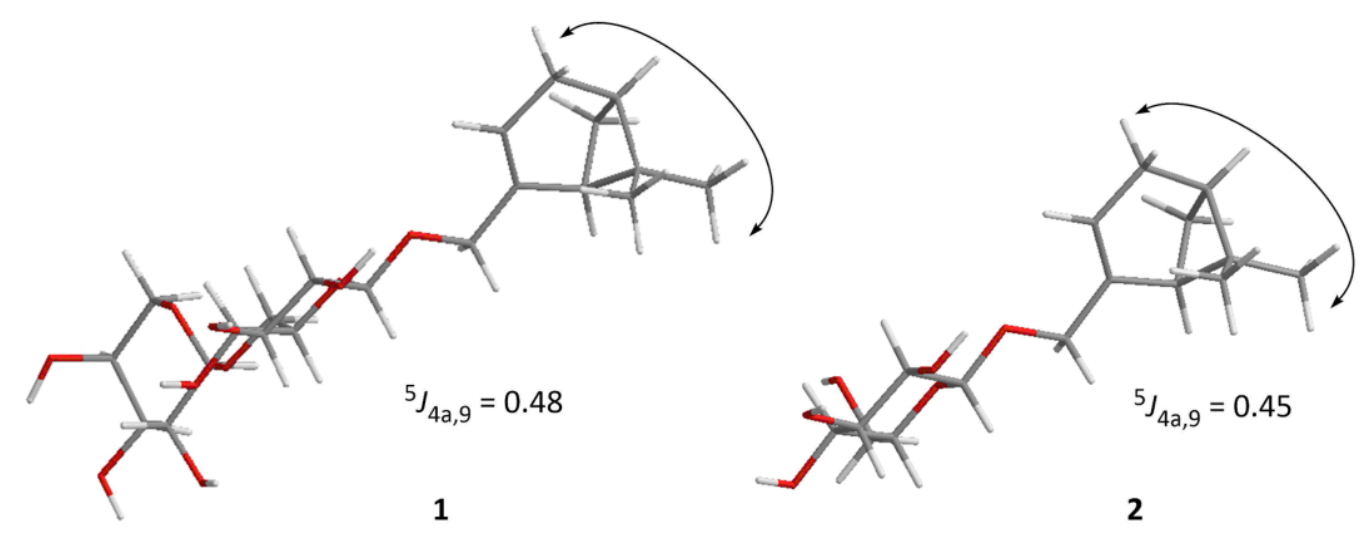

Figure 5. The occurrence of well-resolved and near-identical $(\Delta J=30 \mathrm{mHz}){ }^{5} J_{\mathrm{HH}}$ couplings in 1 and $\mathbf{2}$ are evidence for the highly congruent zig-zag arrangement of their connecting bonds and, thus, their identical relative stereochemistry in both compounds. This $J$-coupling relationship was also verified through $\mathrm{H}, \mathrm{H}$ homodecoupling experiments (see main text). Notably, the different sugar moieties apparently do not affect the geometry of the multicyclic monoterpene moiety and, thus, its zig-zag long-range coupling pathway. 


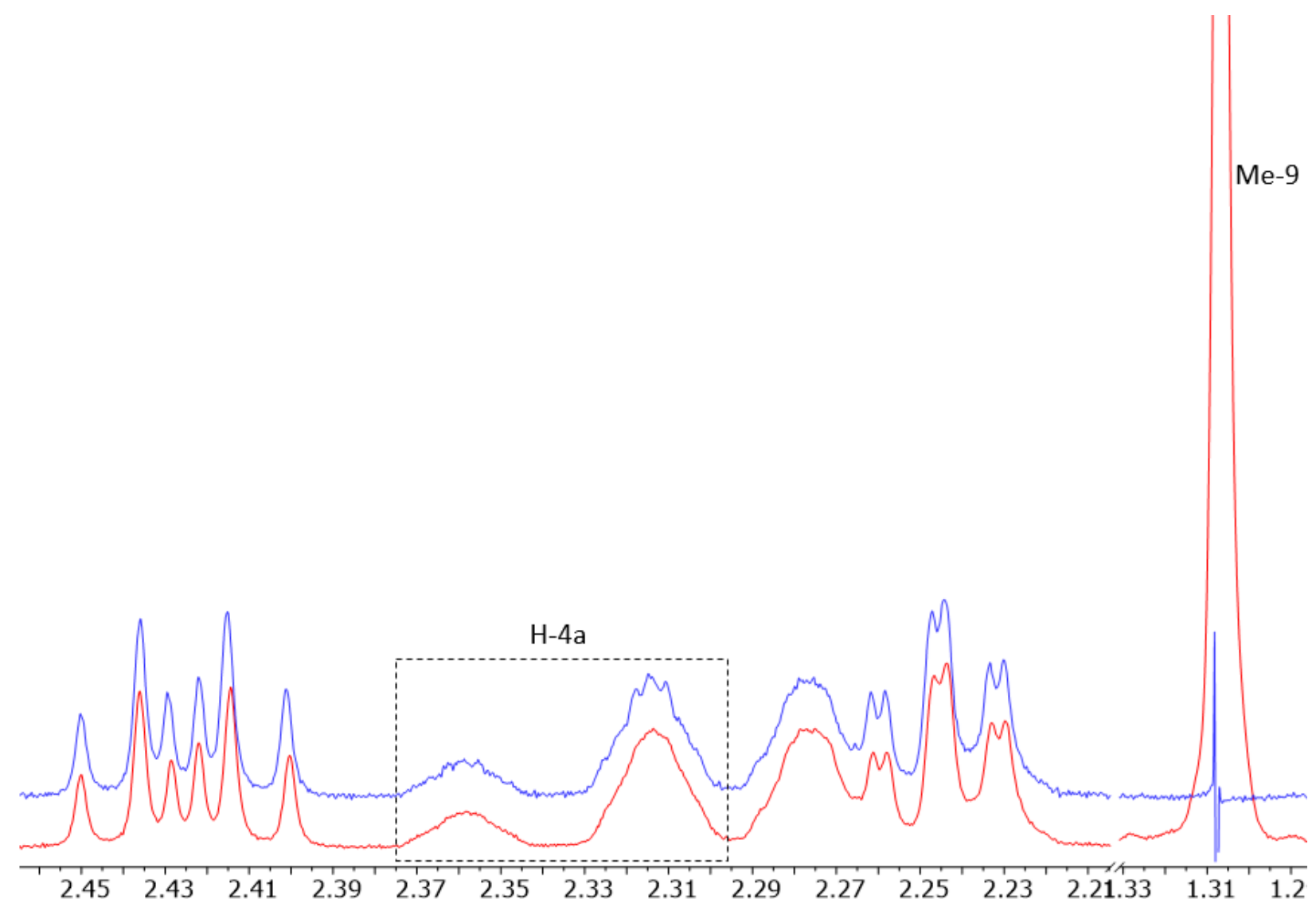

Figure 6. Line-shape comparison for $\mathrm{H}-4 \mathrm{a}$ in $\mathbf{1}$ between homodecoupled (top/blue) and nonhomodecoupled (red) ${ }^{1} \mathrm{H}$ NMR spectra. A Lorentzian-Gaussian apodization function of LB $=-0.3$ $\mathrm{Hz}$ and $\mathrm{GF}=0.05$ was applied to both. The top/blue signals resulted from homodecoupling irradiating Me-9 and exhibit a sharper line-shape in the $\mathrm{H}-4 \mathrm{a}$ resonance, with sub-peaks more observable when compared with that of the corresponding signal in the bottom/red spectrum. 


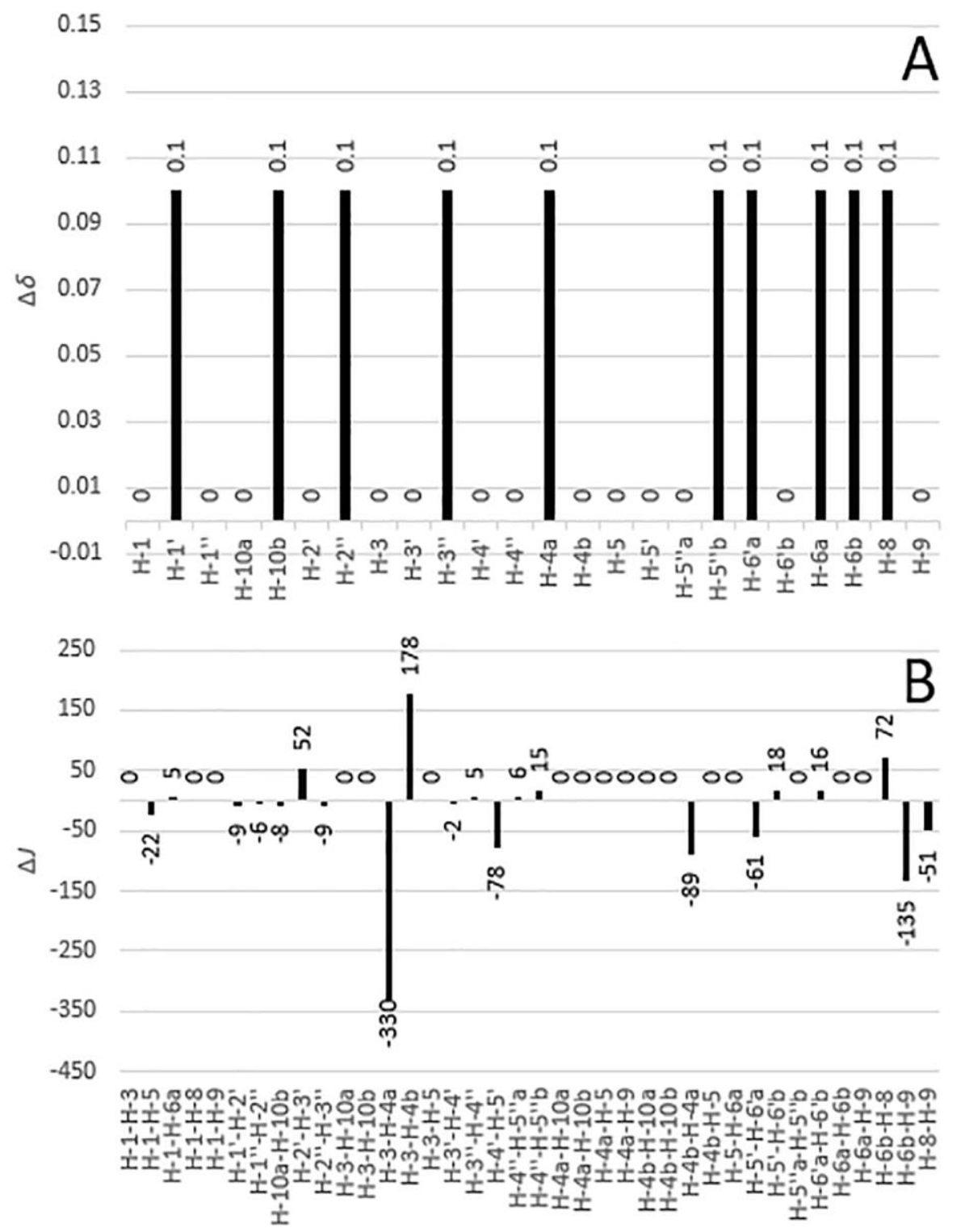

Figure 7. Differences in the chemical shifts (in ppb, A) and coupling constants (in $\mathrm{mHz}, \mathrm{B}$ ) determined by HiFSA using the CT vs the PERCH software tools. As shown in 7A, the chemical shifts have an excellent agreement between $\mathrm{CT}$ and $\mathrm{PERCH}$, for all the resonances $0 \leq \Delta \delta \leq 0.1 \mathrm{ppb}$. 7B shows that the coupling constants also exhibit a good fit with the largest difference for $\Delta J_{\mathrm{H}-3, \mathrm{H}-}$ 4a no more than $-330 \mathrm{mHz}$. 

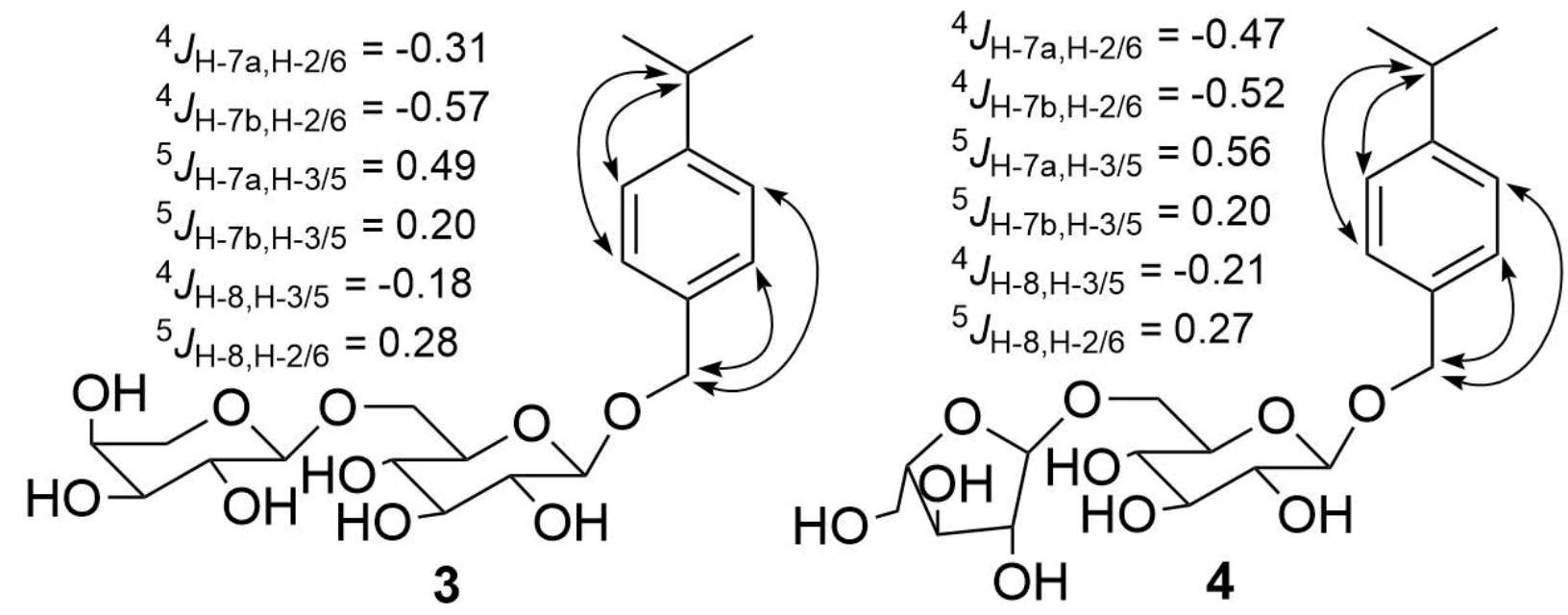

Figure 8. Diagnostic long-range benzylic couplings $\left({ }^{4,5} J_{\mathrm{HH}}\right)$ in $\mathbf{3}$ and $\mathbf{4}$ 
For Table of Contents Only

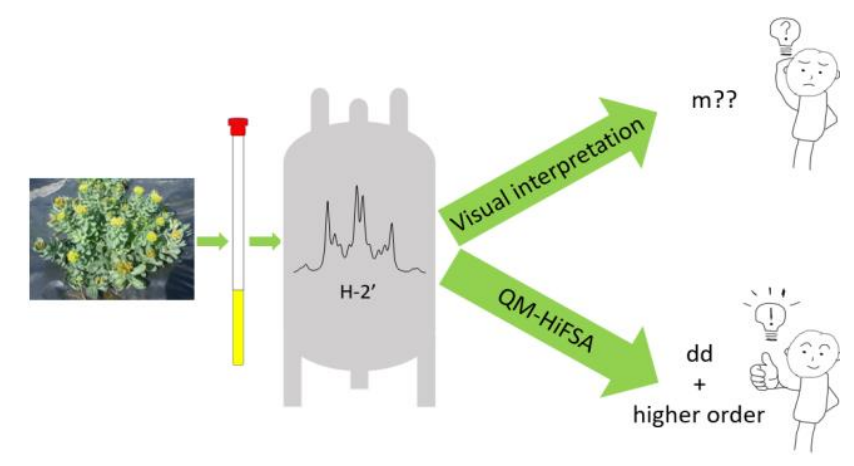

